\title{
TRANSFER OF NERVE BRANCHES OF THE FLEXOR CARPI RADIALIS TO THE POSTERIOR INTEROSSEOUS NERVE
}

\author{
TRANSFERÊNCIA DE RAMOS NERVOSOS DO MÚSCULO FLEXOR \\ RADIAL DO CARPO PARA O NERVO INTERÓSSEO POSTERIOR
}

\author{
Edie Benedito Caetano ${ }^{1}$, luiz Angelo Vieira ${ }^{1}$, Rodrigo Guerra Sabongl ${ }^{2}$, luca Martinez Correio ${ }^{3}$, Kelson Koiti Ogata ${ }^{3}$, \\ EDUARDO BALDY DE SOUSA BONI ${ }^{3}$ \\ 1. Pontifícia Universidade Católica de São Paulo, Faculdade de Ciências Médicas e da Saúde, Department of Orthopedic Surgery, Sorocaba, SP, Brazil. \\ 2. Universidade Federal do Estado de São Paulo (UNIFESP), São Paulo, SP, Brazil. \\ 3. Pontifícia Universidade Católica de São Paulo, Faculdade de Ciências Médicas e da Saúde, Sorocaba, SP, Brazil.
}

\section{ABSTRACT}

Objective: The objective of this paper was to study the anatomical variations of the flexor carpi radialis muscle (FCR) and determine in cadaver limbs whether the FCR nervous branch can be connected to the posterior interosseous nerve (PIN) without tension and how close to the target muscles the transfer can be performed. Method: Thirty cadaveric upper limbs were dissected. Results: The FCR received exclusive innervation of the median nerve, distally to the intercondylar line of the humerus. In 5 limbs, an isolated branch was found and in 25, a common trunk with other nervous branches occurred. We investigated whether the branch for the FCR was long enough to be transferred to the PIN. The diameter of the nerve branch for the FCR corresponded on average to $50 \%$ of the PIN. Conclusion: In 12 limbs, the branch destined to the FCR could be connected to the PIN, distally to the nerve branches to the supinator muscle even during the movements of the forearm and the elbow. In 18 specimens, it was necessary to mobilize the PIN for this innervation. Level of Evidence IV, Case Series.

Keywords: Peripheral nerve injuries. Nerve transfer. Median nerve.

\section{RESUMO}

Objetivo: O objetivo do trabalho foi estudar as variações anatômicas do músculo flexor radial do carpo (FRC) e determinar, em membros de cadáveres, se o ramo nervoso do músculo FRC pode ser conectado ao nervo interósseo posterior (NIP) sem tensão e quão próximo dos músculos alvos a transferência pode ser realizada. Método: Trinta membros superiores cadavéricos foram dissecados. Resultados: O FRC recebeu inervação exclusiva do nervo mediano, distalmente à linha intercondilar do úmero. Em 5 membros encontrou-se um ramo isolado e em 25 ocorreu um tronco comum com outros ramos nervosos. Investigamos se o ramo para o FRC tinha comprimento suficiente para ser transferido para o NIP. O diâmetro do ramo nervoso para o músculo FRC correspondia, em média, a 50\% do NIP. Conclusão: Em 12 membros, o ramo destinado ao FRC poderia ser conectado ao NIP, distalmente aos ramos nervosos para o músculo supinador mesmo durante os movimentos do antebraço e do cotovelo. Em 18 peças foi necessária a mobilização do NIP para essa inervação. Nível de Evidência IV, Série de Casos.

Descritores: Lesões dos nervos periféricos. Transferência de nervo. Nervo mediano.

Citation: Caetano EB, Vieira LA, Sabongi RG, Martinez L, Ogata KK, Boni EBS. Transfer of nerve branches of the flexor carpi radialis to the posterior interosseous nerve. Acta Ortop Bras. [online]. 2018;26(4):222-6. Available from URL: http://www.scielo.br/aob.

\section{INTRODUCTION}

The radial nerve is the most commonly affected in upper limb nerve injuries, causing inability to extend the elbow, wrist, fingers, and thumb. In approximately $12 \%$ of causes it occurs in association with humeral fractures, and may be damaged during trauma, fracture reduction, open reduction and internal fixation, or entrapment in the bone callus., ${ }^{1,2}$ Radial nerve injuries in the lower third of the arm or forearm can usually be repaired by primary suture or reconstruction using nerve grafts, with good restoration of function. High radial nerve injuries near the axilla and posterior cord brachial plexus injuries are especially problematic because the distance and time required for reinnervation of the extensor muscles in the forearm usually impede functional recovery. ${ }^{2-5}$

The repair of a nerve injury is based on primary nerve repair, nerve grafts, tendon transfers, and free muscle transfer. However, there are nerve injuries that are not eligible for primary repair and for which grafts do not provide satisfactory results. These injuries include very proximal nerve injury; extensive area of injury, resulting in a long space between nerve stumps, and idiopathic nerve paralysis or neuritis in which there is no healthy proximal nerve segment. ${ }^{2-4}$ 
In the case of brachial plexus injuries, with very large gaps between nerve endings, there may not be enough time to regenerate the axons and thus reach the motor endplates of the target muscles, before they become permanently resistant to reinnervation. This prolonged period of denervation leaves target muscles susceptible to irreversible degeneration and fibrosis of the motor endplates. ${ }^{2-4}$ Tendon transfers have been performed as first choice to treat radial nerve injuries, but they may be limited as they often prove inconsistent. ${ }^{5-7}$

Plate et al. ${ }^{6}$ are of the opinion that nerve transfers have advantages and are preferable to tendon transfers for the following reasons: transfers can use dispensable or redundant nerves, whereas tendon transfers require sacrifice of the donor muscle; tendon transfers require more extensive dissections, and calculating adequate length and tension is difficult; they have frequently been associated with joint stiffness, disorders of natural muscle biomechanics, fibrosis, impaired vascularization and availability of donor muscles.

In FCR transfers or denervation wrist flexion is preserved by the action of the palmaris longus and flexor carpi ulnaris muscles. The disadvantage of nerve transfers is the time required to reinnervate target muscles. Branches of the median nerve leading to the forearm muscles can be transferred to reinnervate the posterior interosseous nerve (PIN). ${ }^{2-9}$

Clinical series using nerve transfer targeting PIN recovery have been reported with good functional response in patients with high radial nerve and brachial plexus injuries. ${ }^{2-9}$ Despite these promising clinical results, only a few anatomical studies on the nerves involved in these transfers have been described. The flexor carpi radialis (FCR) muscle receives innervation from the median nerve. In most limbs there is only one branch to the FCR. It arises from the lateral epicondyle of the humerus and adjacent areas. In the wrist its tendon passes through a compartment located next to the carpal tunnel, with its insertion point at the base of the second metacarpal bone.

A number of authors ${ }^{4,5}$ have transferred the nerve leading to the FCR to the PIN, given its synergistic relationship with the wrist and finger extensors, including thumb movement. The selection of donor nerves with a synergistic relationship with the recipient nerves facilitates subsequent cortical integration. Flexion of the wrist increases the passive tension of the finger extensors and thus causes their extension, increasing the extension force, while wrist extension has the opposite effect and allows passive finger flexion..$^{5-10}$

The aim of this study was to assess, in 30 cadaveric limbs, whether the median nerve branch leading to the FCR muscle can or cannot be connected to the PIN without tension, and how close to the target muscles the transfer can be performed.

\section{MATERIALS AND METHODS}

This study was based on the dissection of 30 limbs from 15 male cadavers. Each forearm was dissected in the elbow extension and forearm pronation position. None of the cadavers showed evidence of deformities or previous surgical procedures on the forearm. The median nerve was identified in the arm and dissected from proximal to distal. The bicipital aponeurosis was sectioned. The pronator teres muscle (PTM) was disinserted distally. The branches of the median nerve to the PTM, FCR, PL, FDS (flexor digitorum superficialis) muscles and the AIN (anterior interosseous nerve) with its branches leading to the flexor digitorum profundus (FDP), flexor pollicis longus (FPL) and $P Q$ (pronator quadratus) were dissected.

We identified the branches of the radial nerve to the brachialis, brachioradialis, extensor carpi radialis longus (ECRL), and extensor carpi radialis brevis (ECRB) muscles, superficial branch of the radial nerve (SBRN), PIN and their branches to the supinator muscle (SM). Vascular structures were not preserved to facilitate dissection of the nerves. We measured forearm length from the center of a line between the medial and lateral epicondyles (intercondylar line) to the center of a line between the radial and ulnar styloid processes. The origin of the branch of the MN to the FCR was measured from the intercondylar line. We used a magnifying glass with $2.5 x$ magnification, a ruler and a digital caliper to measure the length and diameter of the donor (MN) and recipient (PIN) nerves at certain stages of the dissection. The measurement of the branches to the FCR was taken in 14 limbs, and PIN was measured in 30 limbs. This study was approved by the Institutional Review Board under opinion number 1.611.295

In the first anatomical study, the branches of the supinator were transferred to the posterior interosseous nerve. We measured the posterior interosseous nerve and branches to the supinator in 30 limbs. The branches of the median nerve to the muscles: pronator teres, flexor carpi radialis, palmaris longus, flexor digitorum superficialis, and anterior interosseous nerve were measured in only 14 limbs. The initial idea was to also measure the branches of the median nerve in 30 limbs (there are five branches of the median nerve). It is very tiring and laborious to take these measurements with a digital caliper in 30 limbs. We considered the measurement in 14 branches to be sufficient for the research.

\section{RESULTS}

The results of anatomical measurement of donor and recipient nerve length and diameter are shown in Table 1 . The mean forearm length was $26.2 \pm 2.7 \mathrm{~cm}$. The patterns of branching and distribution of the branches of the MN to the FCR muscle that we recorded in 30 limbs are presented below. The presence of only one branch to the FCR was identified in all limbs, in most cases it was the third muscle of the forearm to be innervated by the median and received exclusive innervation from this nerve in all limbs (Figure 1A). The intercondylar line of the humerus originated distally in all limbs. In 5 limbs it received innervation from an isolated branch (Figures $1 \mathrm{~A}$ and $1 \mathrm{~B})$. In 8 from a common trunk with one of the branches of the PTM, being 2 with the first branch, 5 with the second branch (Figure 2A), and one with the third branch of the PTM.

In 8 from a common trunk with the branch leading to the PL muscle (Figure 2B). In 4 from a common trunk with branches to the PTM and $\mathrm{PL}$ (Figures $3 \mathrm{~A}$ and $3 \mathrm{~B}$ ). In 3 from a common trunk to the FDS muscle (Figure $4 A$ ), and in 2 from a common trunk to the PTM, PL, FDS (Figure 4B) and (Table1).

The results of anatomical measurement of donor and recipient nerve length and diameter are described in Table 2. The length of the PIN was measured from its origin in the radial nerve to the distal margin of the SM. In 14 of the 30 dissected limbs, we assessed the possibility of transferring the branch from the MN leading to the FCR to the PIN without tension, relating to forearm and elbow movements. The mean diameter of the nerve to the FCR corresponds to $50 \%$ of the PIN diameter.

Table 1. Results of anatomical measurement of the length and diameter of the donor (FCR) and recipient (AIN) nerves.

\begin{tabular}{c|c|c|c}
\hline & $\begin{array}{c}\text { Number of } \\
\text { branches in } \\
30 \text { limbs }\end{array}$ & $\begin{array}{c}\text { Mean diameter } \\
\text { in } \mathbf{~ m m}\end{array}$ & $\begin{array}{c}\text { Mean length of } \\
\text { the nerve in } \mathrm{mm}\end{array}$ \\
\hline $\begin{array}{c}\text { Branch of median } \\
\text { nerve to flexor } \\
\text { carpi radialis }\end{array}$ & 1 in 30 limbs & $\begin{array}{c}1.5 \pm 0.4 \text { measured } \\
\text { in } 14 \text { limbs }\end{array}$ & $4.0(3.0 \pm 5.2)$ \\
\hline $\begin{array}{c}\text { Posterior } \\
\text { interosseous nerve }\end{array}$ & 1 in 30 limbs & $\begin{array}{c}3.0 \pm 0.5 \text { measured } \\
\text { in } 30 \text { limbs }\end{array}$ & $5.2(6.5 \pm 2.5)$ \\
\hline
\end{tabular}



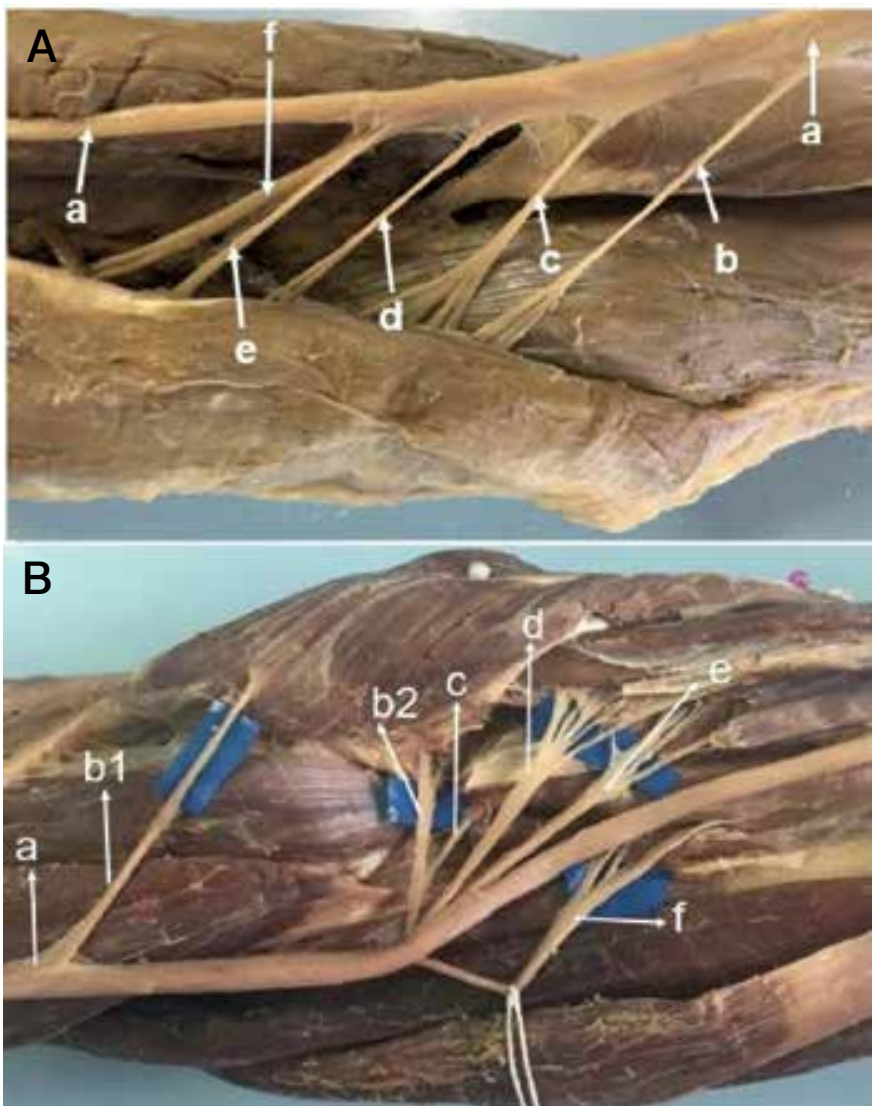

Figure 1. A. (a) median nerve; (b) branch from the pronator teres; (c) branch to the palmaris longus; (d) branch to the flexor carpi radialis; (e) branch to the flexor digitorum superficialis; (f) anterior interosseous nerve. B. (a) median nerve; (b1) first branch from the pronator teres; (b2) second branch from the pronator teres; (c) branch to the palmaris longus; (d) branch to the flexor carpi radialis; (e) branch to the flexor digitorum superficialis; (f) anterior interosseous nerve.

\section{DISCUSSION}

Anatomical treatises describe the classic distribution of the median nerve in the forearm: two branches (upper and lower) to the PTM, a trunk common to the FCR and PL and a branch to the FDS.10,11 Some studies have revealed considerable variations of this pattern in several anatomical series. ${ }^{4,12-16}$

Sunderland and Ray ${ }^{12}$ found a single branch to the FCR in 18 limbs and two branches in two limbs in 19 of the 20 from a common trunk with branches to other forearm muscles. Canovas et al. ${ }^{13}$ dissected 10 limbs, finding considerable variability in the branches to the muscles innervated by the median. Chantelot et al..$^{14}$ dissected 50 limbs, and found the classic distribution (one common trunk for the FCR and PL in only 20 limbs) (40\%). Zawawy et al., ${ }^{15}$ reported that in 20 limbs they identified only one branch to the FCR in 14 limbs $(70 \%)$, originating as a single branch or in common with branches leading to other muscles. In 6 of the 20 limbs, they observed that the FCR muscle received 2 separate branches of the median nerve. Blair and $\mathrm{Joos}^{16}$ dissected 20 limbs and reported that the FCR muscle received innervation from the median nerve in all of them. In the majority of limbs the muscle received innervation both from this nerve and from branches of the AIN.

In this study we recorded that only one branch of the median nerve led to the FCR muscle, originating distally to the epicondylar line of the humerus, in five limbs without sharing with branches to other muscles, and in 25 sharing innervation with other muscles of the
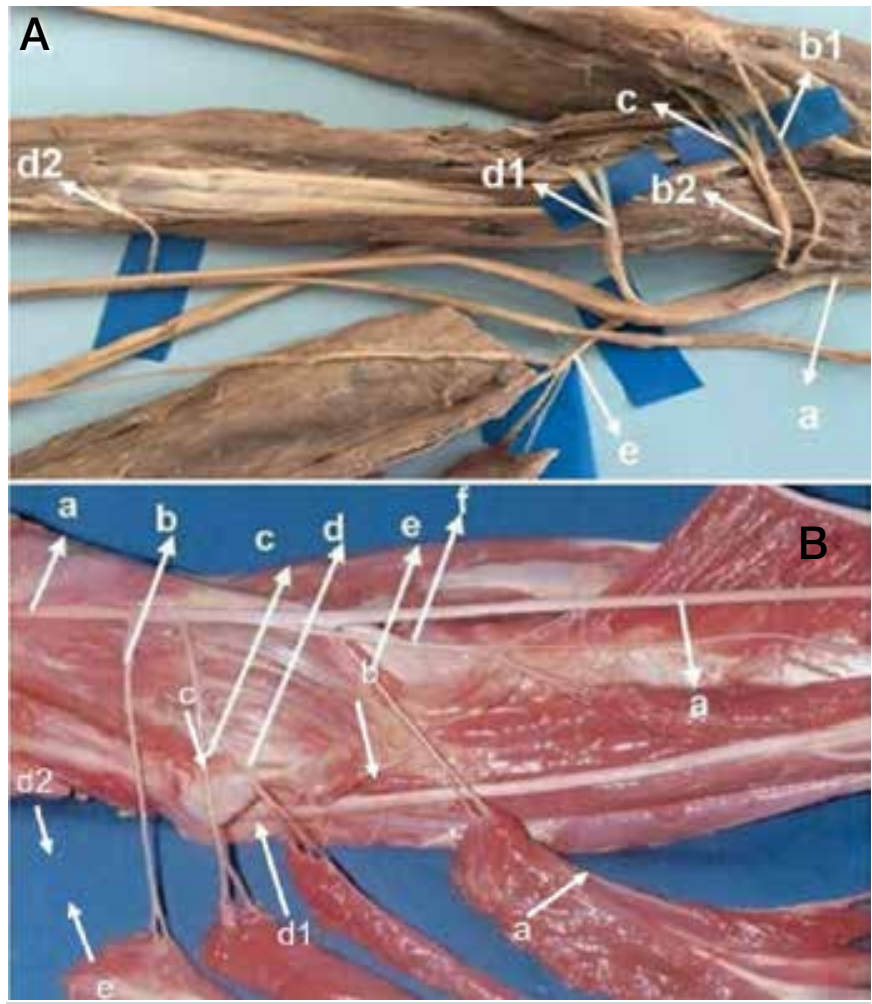

Figure 2. A. (a) median nerve; (b1) first branch from the pronator teres; (b2) second branch from the pronator teres; (c) branch to the flexor carpi radialis; (d1 and d2) branches to the flexor digitorum superficialis; (e) anterior interosseous nerve; palmaris longus absent. B. (a) median nerve; (b) branch from the pronator teres; (c) branch to the palmaris longus; (d) branch to the flexor carpi radialis; (e) branch to the flexor digitorum superficialis; $(f)$ anterior interosseous nerve.

forearm. We identified the classic pattern of FCR innervation, that is, a common trunk with the $\mathrm{PL}$, in 8 limbs (26.5\%). These anatomical details are not an absolute clinical necessity in preparation for a nerve transfer to restore finger extension, but knowledge of these details facilitates the identification of these nerve branches. ${ }^{17}$

Lowe et al. ${ }^{3}$ proposed the transfer of branches from the median nerve to the FDS to reinitiate the PIN; since the FDS branch is an antagonist of the digital extensors, the result of this procedure was unsatisfactory. Ray and Mackinnon ${ }^{4}$ subsequently transferred the branch of the MN to the FCR to the PIN, and achieved positive clinical results in 18 of the 19 patients, considering synergistic relationships of this transfer. Recovery of motor function tends to be better after radial nerve injury than median or ulnar nerve injury, largely because it is composed mainly of motor fibers and innervates only the extrinsic muscles. ${ }^{18}$

The transfer of the branch of the median nerve leading to the FCR provides several advantages. Firstly, it reduces the distance between the donor and recipient branches, facilitating a faster recovery than nerve suture or graft. Secondly, wrist extension function is maintained by the action of the extensor carpi ulnaris, which receives innervation from the ulnar nerve. Thirdly, the branches of the FCR and PIN are motor nerve branches, although the PIN contains sensory axons, most of them are motor axons. ${ }^{2,4}$

In this anatomical study we adopted the following procedure: ${ }^{2}$ the branch for the FCR muscle was sectioned at the neuromuscular junction and directed laterally to be connected to the PIN. The sectioning of the latter depends on each situation, and must be decided during the surgical procedure. In 12 limbs we noticed 

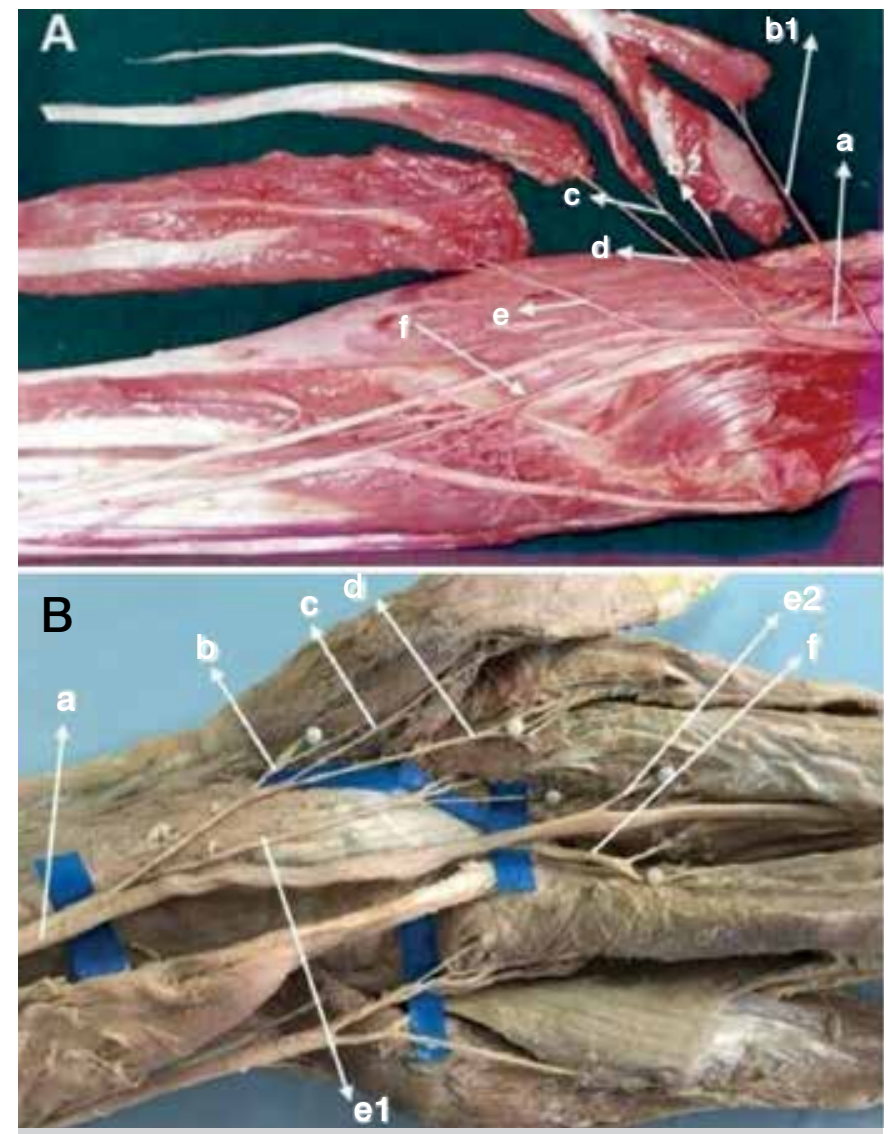

Figure 3. A. (a) median nerve; (b1) branch to the ulnar head of the pronator teres; (b2) branch to the humeral head of the pronator teres; (c) branch to the palmaris longus; (d) branch to the flexor carpi radialis; (e) branch to the flexor digitorum superficialis; (f) anterior interosseous nerve. B. (a) median nerve; (b) branch to the pronator teres; (c) branch to the palmaris longus; (d) branch to the flexor carpi radialis; (e1) first branch to the flexor digitorum superficialis; (e2) second branch to the flexor digitorum superficialis ( $f$ ) anterior interosseous nerve.

that the branch of the FCR was of sufficient length to reach the PIN distally to the point of origin of the branches to the SM, free of tension even with forearm and elbow movements (Figure 5A), and with the advantage that donor nerve axons were not wasted in the unnecessary innervation of the SM, because due to its anatomical characteristics, this muscle is not used in tendon transfers and supination is maintained by the action of the biceps brachii (BB). In 18 limbs the branches to the SM (usually two or more branches) were sectioned to allow the PIN to be moved medially to shorten the distance, in order to make the connection to the branch of the FCR. The SM was sectioned longitudinally, following the course of the PIN, from the Arcade of Frohse to the distal margin of the SM. In this way, the PIN was released and could be mobilized medially towards the branch of the FCR and connected without tension (Figure 5B).

This mobilization is facilitated by the sectioning of the branches leading to the SM, which tend to retain the PIN nerve, restricting its excursion towards the median nerve. The sectioning of the branches leading to the SM also allows all the PIN axons to be directed to muscle groups that provide wrist and finger extension, avoiding the loss of critical axons in redundant functions, since the supination function is preserved by the action of the biceps brachii. The branch to the FCR muscle is sectioned as long as possible and innervated as much as possible without damaging
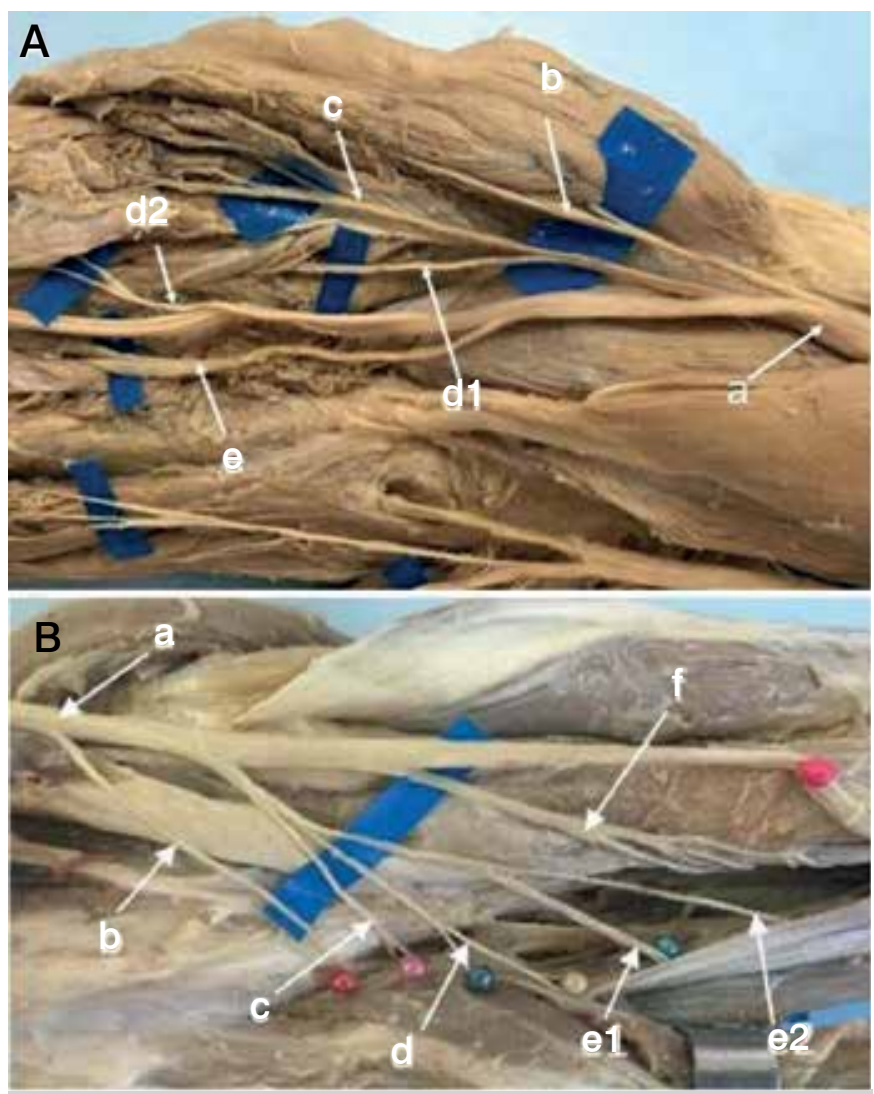

Figure 4. A. (a) median nerve; (b) branch to the pronator teres; (c) branch to the flexor carpi radialis; (d) branch to the flexor digitorum superficialis; (e) anterior interosseous nerve; palmaris longus absent. B. (a) median nerve; (b) branch to the pronator teres; (c) branch to the palmaris longus; (d) branch to the flexor carpi radialis; (e1) first branch to the flexor digitorum superficialis; (e2) second branch to the flexor digitorum superficialis (f) anterior interosseous nerve.

Table 2. Distribution of branches of the FCR muscle, according to number of branches and sharing of innervation with branches to other muscles.

\begin{tabular}{|c|c|c|c|c|c|c|c|c|c|c|c|}
\hline & Bran & iches & $\begin{array}{c}\text { No } \\
\text { Sharing }\end{array}$ & & & & & & Sharing & Limbs & Absent \\
\hline & 1 & 23 & & PTM & PL & FCR & FDS & AIN & & & \\
\hline FCR & 30 & -1. & 3 & 8 & 8 & $\cdots$ & 3 & $-\cdots$ & $\begin{array}{c}\text { PTM+PL+FDS (3) } \\
\text { PTM+PL (3) } \\
\text { FDS+AIN (2) }\end{array}$ & 30 & 0 \\
\hline
\end{tabular}

its axons. To favor axon regeneration, it is desirable to perform nerve cooptation, as close as possible to the target muscle, without tension in the sutures. Sukegawa et al. ${ }^{2}$ recommends that once the meeting point between donor and recipient has been identified, the latter should be sectioned $5 \mathrm{~mm}$ proximal to this point in order to avoid tension in the suture thread. This was done, thus imitating the in vivo procedure in cadaver limbs. It is possible to combine this with the transfer of the nerve to the PL to the FCR, increasing the availability of donor axons. The disadvantage is that an important source of potential subsequent tendon transfer is lost.

We identified that the mean diameter of the branch leading to the FCR muscle recorded in 14 limbs was $1.5 \pm 0.4$, which corresponds to $50 \%$ of the diameter of the PIN was $3.0 \pm 0.5$ in 30 limbs. Several studies described in the literature show that nerve transfers of branches with considerable difference in diameter and of nerve 

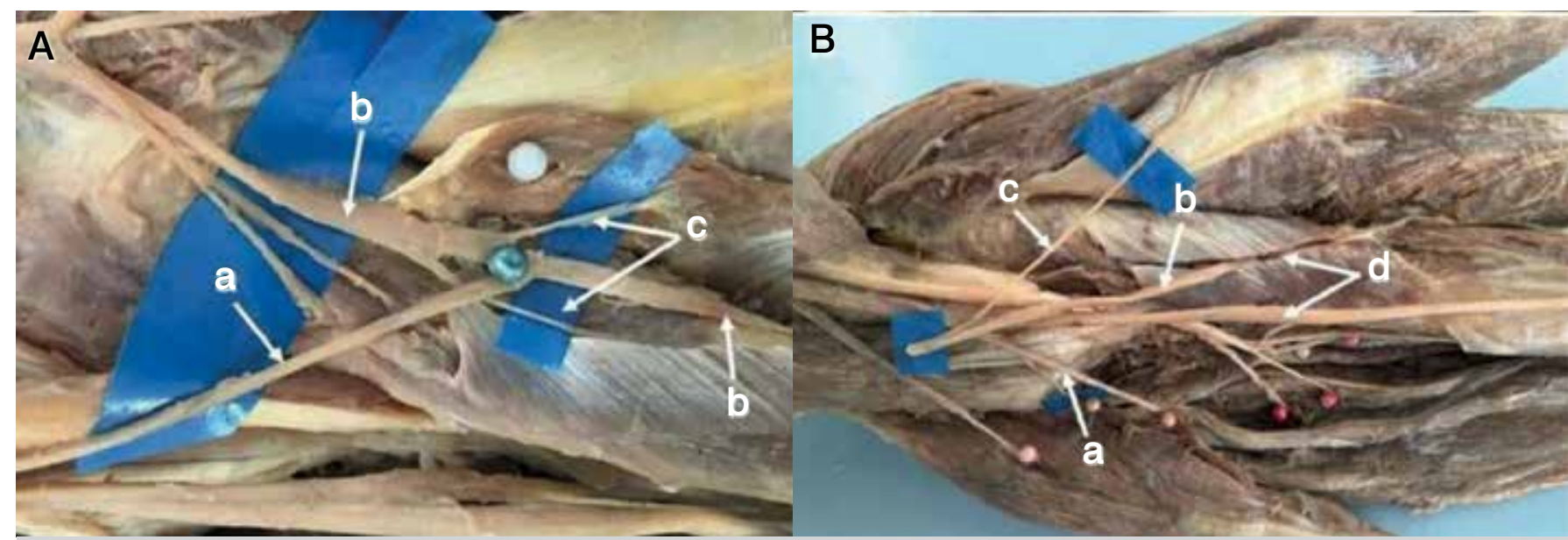

Figure 5. A. In 12 limbs we were able to connect the branch leading to the flexor carpi radialis (a) to the interosseous nerve (b), distally to the branches to the supinator muscle (c) without tension, even during forearm pronosupination and elbow flexion/extension movements. B. In 18 limbs it was necessary to mobilize the posterior interosseous nerve (b) for the connection with the branch to the flexor carpi radialis muscle (a); branch to the extensor carpi radialis brevis (c); supinator muscle (d).

fibers provide good results. De Medinaceli' ${ }^{19}$ believes that the reinnervation of $20-30 \%$ of muscle fibers is compatible with normal muscle function. Jiang et al. ${ }^{20}$ state that the axons in the proximal stump can multiply up to 3 - to 4 -fold. Therefore, the donor nerve must have at least $30 \%$ of the number of axons of the recipient nerve. Sukegawa et al. ${ }^{2}$ describe in their studies that the branch of the $\mathrm{MN}$ to the FCR contained approximately $30 \%$ of the number of axons in the PIN, which is theoretically sufficient to achieve its good recovery. Other factors support the justification for this nerve transfer, even if the mean diameter of the branch of the $\mathrm{MN}$ to the FCR muscle is $50 \%$ of the mean diameter of the PIN, for instance, muscle strength required for finger and thumb extension is minimal, since we need little strength to open our hand, the muscle strength required for gripping is greater than for release. ${ }^{7}$

\section{CONCLUSIONS}

The FCR muscle received exclusive innervation from the median nerve. In 25 limbs (83\%), from a common trunk with branches to other muscles of the forearm, we observed that in 12 limbs, the branch leading to the FCR could be connected to the PIN, distally to the branches to the SM, even during the forearm and elbow movements. In 18 limbs it was necessary to mobilize the PIN for this connection.

AUTHORS' CONTRIBUTIONS: Each author made significant individual contributions to this manuscript. LM (0000-0002-6263-2527) ${ }^{\star}$, KKO (0000-00029814-4912)* and EBSB (0000-0002-6887-2185)* bibliographical survey and assistance in the anatomical dissections; RGS (0000-0003-0164-3596)* analysis of results and writing of the article; LAV (0000-0003-4406-2492)* writing of the article and photographic documentation. EBC (0000-0003-4572-3854)* was present in all the dissections, writing and revision of the article, analysis of results and intellectual concept of the article and creation of the entire research project. *ORCID (Open Researcher and Contributor ID).

\section{REFERENCES}

1. Pet MA, Lipira AB, Ko JH. Nerve transfers for the restoration of wrist, finger, and thumb extension after high radial nerve injury. Hand Clin. 2016;32(2):191-207.

2. Sukegawa K, Suzuki T, Ogawa Y, Kobayashi T, Matsuura Y, Kuniyoshi K. A cadaver study of median-to-radial nerve transfer for radial nerve injuries. J Hand Surg Am. 2016;41(1):20-6.

3. Lowe JB III, Sen SK, Mackinnon SE. Current approach to radial nerve paralysis. Plast Reconstr Surg. 2002;110(4):1099-113

4. Ray WZ, Mackinnon SE. Clinical outcomes following median to radial nerve transfers. J Hand Surg Am. 2011;36(2):201-8

5. Bincaz LE, Cherifi $\mathrm{H}$, Alnot JY. [Palliative tendon transfer for reanimation of the wrist and finger extension lag. Report of 14 transfers for radial nerve palsies and 10 transfers for brachial plexus lesions]. Chir Main. 2002;21(1):13-22.

6. Plate JF, Ely LK, Pulley BR, Smith BP, Li Z. Combined proximal nerve graft and distal nerve transfer for a posterior cord brachial plexus injury. J Neurosurg. 2013;118(1):155-9.

7. Bertelli JA, Kechele PR, Santos MA, Besen BAMP, Duarte H. Anatomical feasibility of transferring supinator motor branches to the posterior interosseous nerve in C7-T1 brachial plexus palsies. Laboratory investigation. J Neurosurg. 2009;111(2):326-31.

8. Ustün ME, Ogun TC, Büyükmumcu M. Neurotization as an alternative for restoring finger and wrist extension. J Neurosurg. 2001;94(5):795-8.

9. Ukrit A, Leechavengvongs S, Malungpaishrope K, Uerpairojkit C, Chongthammakun S, Witoonchart K. Nerve transfer for wrist extension using nerve to flexor digitorum superficialis in cervical 5, 6, and 7 root avulsions: anatomic study and report of 2 cases. J Hand Surg Am. 2009;34(9):1659-66.
10. Paturet G. Traité d'anatomie humaine. Paris: Masson; 1954

11. Rouvire H, Delmas A. Anatomie humaine. Paris: Masson; 1984

12. Sunderland S, Ray LJ. Metrical and non-metrical features of the muscular branches of the median nerve. J Comp Neurol. 1946;85:191-203.

13. Canovas F, Mouilferon P, Bonnel F. Biometry of the muscular branches of the median nerves to the forearm. Clin Anat. 1998;11(4):239-45.

14. Chantelot C, Feugas C, Guillem P, Chapnikoff D, Rémy F, Fontaine C. Innervation of the medial epicondylar muscles: an anatomic study in 50 cases. Surg Radiol Anat. 1999;21(3):165-8.

15. Zawawy EME, Sekily NME, Fouad WA, Emam MH, Hassan MM. Median nerve motor entry points in the forearm: clinical application. Eur $\mathrm{J}$ Anat. 2016;20(1):1-17.

16. Blair W, Joos K. The innervation of the flexor carpi radialis: and interfascicular dissection. Arch Neurol. 1982;39(10):647-9

17. Brown JM, Tung TH, Mackinnon SE. Median to radial nerve transfer to restore wrist and finger extension: technical nuances. Neurosurgery. 2010;66(3 Suppl Operative):75-83.

18. Guerra WK, Baldauf J, Schroeder HW. Long-term results after microsurgica repair of traumatic nerve lesions of the upper extremities. Zentralbl Neurochir. 2007;68(4):195-9.

19. De Medinaceli L, editor. Cell surgery to repair divided nerves. New York: CASIS-CID; 1994

20. Jiang BG, Yin XF, Zhang DY, Fu ZG, Zhang HB. Maximum number of collaterals developed by one axon during peripheral nerve regeneration and the influence of that number on reinnervation effects. Eur Neurol. 2007;58(1):12-20. 